\title{
Surmounting Stereotyping of International Students
}

\author{
Aini Syahira Jamaluddin \\ School of Education and Human Sciences, Al-Bukhary International University, Alor Star, Kedah, Malaysia \\ Faizah Idrus \\ Department of Language and Literacy, International Islamic University Malaysia, Kuala Lumpur, Malaysia
}

\begin{abstract}
This study attempted to investigate the experiences of international students towards stereotyping inside and outside of the campus. The purpose of this study was to explore the students' experiences on stereotyping and employed qualitative method as the mode of inquiry. Semi-structured interview was conducted with five postgraduates' students in one of the public universities in Malaysia. The respondents came from different countries and majors of studies. Finding from the study found that international students did experience stereotyping, but this encounter seemed not to affect their studies. Finally, future researchers are encouraged to adapt this study within a larger group of respondents to examine its confirmability and credibility. A careful exploration of stereotype in the areas of intercultural and cross-cultural communication among international students may provide more insights into their wellbeing in countries away from home.
\end{abstract}

Index Terms - stereotyping, higher education, international students, intercultural communication, multicultural communities

\section{INTRODUCTION}

\section{Background of the Study}

The higher education, private or public universities and colleges are not only attracting secondary-school leavers to pursue their studies, but also working and mature individuals. With globalization, Malaysia has become an international education hub for students to pursue their higher education. With a total of more than 80,688 graduates in this university coming from more than 125 countries worldwide (Office of International Affairs, IIUM, 2020), the cross-cultural and intercultural communication are inevitable. It cannot be denied that international students face problems in adapting to a new environment, despite many efforts made to make them feel welcomed. Two of the most challenging problems are among others communication and miss-communication, which potentially lead to discrimination, bias, prejudice and stereotyping. The role of intercultural communication thus is pertinent in this concept. Intercultural communication can be defined as a communication of different cultures between individuals (Chen \& Starosta, 1998). It could be in the forms of different races or ethnicities, socioeconomic status etc. Intercultural communication, in fact, offers chances and insight into exploring people's relationships in socially and culturally diverse societies. The higher education (HE) is expected to provide a social environment for society with harmonization albeit cultural diversity. Effective education for cultural diversity is largely dependent upon successful classroom practices, and most important of all, on effective communication between teachers, students and the community (www.docplayer.hu, 2011). HE should look for situations in that they can promote counter-stereotypical images of underrepresented groups and avoid biasness. This is important for staff and students of those institutions. If people in communities are always presented with an image of certain groups of people in certain roles, then the association becomes automatic and influences our view of that group of people and that role (Natalia, 2011). For instance, many literatures mentioned the association of black people with crimes and being uneducated or Chinese students with the mathematical ingenuity. HE needs to prepare staff and local students to acknowledge that while international students come from diverse backgrounds and cultures and may be very different in demographic and educational characteristics, they are sufficiently different from the locals to be treated as a separate entity (www.repository.um.edu.my)

Quite a handful of researchers carried out studies on international students' experiences on stereotyping in other parts of the world especially in European countries. A study conducted in Malaysia regarding international students and stereotyping and biasness was conducted by Pandian (2008) on Middle Eastern Students' Perceptions and Experiences in a Malaysian University. Since 2008, very few studies are found on this particular topic, thus there is a need to do a more extensive study on students' experiences on stereotyping and biasness in a multicultural Malaysia. It has been reported that local students are not aware of them being bias or practicing stereotyping. This is due to lack of cultural awareness and knowledge about others' cultures. As stated by Idrus (2021), Cultural Intelligence (CQ) should be inculcated and learned at a very early age for everyone especially in multicultural societies. Cultural intelligence can be understood as the capability to relate and work effectively across different cultures. Idrus further clarified that Cultural Intelligence is an individual's ability to wanting to know the cultures of others. This drive comes from the awareness 
and knowledge about that 'others' and that the individual is willing to go beyond their daily norms. This is to avoid miscommunication and potential problems. Problems occurred are typically related to cultural adaption or are not able to being culturally responsive and not equipped with enough knowledge and exposure of cultural diversity. Thus, this ineptitude might affect students' academic performance and influence the growth and development of graduate students. Only certain situations have been revealed to involve discrimination, prejudice, tolerance, and stereotypes, but these encounters are rare and not rampant (Pandian, 2008). Therefore, the purpose of this current study was focused on investigating IIUM postgraduate international students' experiences in perceiving 'stereotyping' and to examine the ways they overcome being stereotyped. It is imperative to understand the problems faced by international students that are related to stereotyping in light of the notion and theories of inter-cultural communication.

\section{LITERATURE REVIEW}

\section{A. Internationalization through Education}

During the Balkan War in 1990, there was a major movement of refugees and international migrants. One of the aftermaths of the migration was that it has changed people's perceptions of the cultures of others in many different ways (cited in Bhugra, 2005). In terms of education, as claimed by Line Verbik and Lasanowski (2007) the pattern of migrations for the sake of education has changed significantly after the incident of September 11. In the Asia continent, there were positive changes in the government's education policies, thus it has led international students to choose Asia as one of the potential destinations to study, including Malaysia (Zeeshan, 2013). It can be seen in Malaysia the enrollment of international students had increased from 30,397 in 2003, to 100,000 students in 2010. The 2018's statistics reported the number of international students was 130,245 (Ministry of Higher Education, 2018).

The Ministry of Higher Education Malaysia has made a recent move to transform the landscape of tertiary education where one main thrust aims at intensifying internationalization and ensuring a $10 \%-30 \%$ enrolment of international students (www.web.usm.my, 2008). This phenomenon is inextricably linked to rapid racial and ethnic diversification of its student body. Malaysia faces challenges in creating a new multi-channeled learning environment where international and local students study, connect and work with one another across classrooms, community and country borders in many exciting ways (www.csis.prod.s3.amazonaws.com, 2018).

The existence of multiracial community has created a chance for intercultural and cross-cultural communication to happen. While cross-cultural deals with the comparison of different cultures, intercultural describes communities in which there is a deep understanding and respect for all cultures. In cross-cultural communication, differences are understood and acknowledged, and can bring about individual change, but not collective transformations. In crosscultural societies, one culture is often considered "the norm" and all other cultures are compared or contrasted to the dominant culture (www.zenaconsulting.com, 2020). The interaction is not easy to be built because it has found as potentially challenging due to the cultural and education background among international and local students (Bartlett, 2002). Hence, students feel more comfortable forming friendship and interacting with other students who have the same backgrounds. This in the end will lead to differences in daily social activities and lack of interaction among those two groups. The interaction between local and international students is found as one of the central issues that is increasing in internationalizing teaching and learning strategies in universities, even though internationalizing content was considered as easy to be addressed. Lack of exposure or interaction with international students or people with different cultures might lead students to create a certain stereotype because they only mainly depend on their prior knowledge of a particular group of people.

\section{B. Intercultural Communication in Higher Education}

Intracultural communication is a meaningful exchange between members of the same social group or of groups with similar cultural properties (Hashem, 2017). Such groups may be distinguishable from the mainstream society on the basis of race, ethnicity, tradition, values, religious faith, economic level, gender, age, or other traits and abilities (www.onlinelibrary.wiley.com, 2013). Culture and communication are closely related. The more people share in common, the easier their connections. Samovar (1998) defined intercultural communication as "communication between people whose cultural perceptions and symbol systems are distinct enough to alter the communication event' (p. 48), while Chen and Starosta (1998) characterized intercultural communication as 'the communication between people from two different cultures' (p. 28). Based on these definitions, it can be inferred that cross-cultural communication occurs when both parties have distinct differences and these differences affect the process of communication (cited in Lindner, 2013) The aims of intercultural communication include decreasing misunderstanding (Chen and Starosta, 1998), tolerating cultural diversity (Gudykunst and Kim, 1984), expanding Cultural Intelligence knowledge (Idrus, 2021) and developing adaptive culture (Dodd, 1991).

Based on Pandian (www.usm.web.my, 2008) many areas of intercultural activities have been linked as part of graduate school's work and the exploration is still needed since the number of international students is multiplied in numbers. There are many vital reasons for international students to pursue their studies oversea and leave their countries. Some might feel the need to obtain quality higher education to equip themselves with employable international skills, to establish multicultural relationships with domestic students and to acquire skills that are vital for their country's 
economy in the age of globalization and knowledge-based economies (Pandian, 2008). The enrolment of international students in university has benefited the economies of students' countries of origin, the host country's economy and students themselves, be it international or local students (Pandian, 2008). This combination of international and local students heightened the stature of educational institutions which provides a rich diversity academically, and socially, thus leading to the construction of multitudes of multicultural learning environment.

\section{Higher Education Institutions in Malaysia}

It is the Ministry of Education's aspiration to explore challenges as well as opportunities in dealing with the increasing numbers of students from various countries and cultures all over the world (https://www.moe.gov.my, 2013) International students provide the best platform for cross-cultural and intercultural learning and communication. However, it is undeniable that the students themselves may also face many challenges and barriers that might interrupt their learning experiences. Due to their differences in cultural-education background, international students pursuing their studies in foreign countries found that interacting with local students and university staff as potentially challenging (Bartlett, 2002).

TABLE 1

NUMBERS OF INTERNATIONAL STUDENTS IN MALAYSIA

\begin{tabular}{llll}
\hline Countries & $\mathbf{2 0 1 7}$ & $\mathbf{2 0 1 8}$ & $\mathbf{2 0 1 9}$ \\
\hline Bangladesh & 30,829 & 34,455 & 30,525 \\
China & 12,947 & 11,718 & 14,854 \\
Nigeria & 10,775 & 15,262 & 13,529 \\
Indonesia & 8,956 & 8,653 & 9,762 \\
Yemen & 5,294 & 5,942 & 6,248 \\
Pakistan & 4,507 & 5,292 & 6,033 \\
Libya & 3,130 & 3,246 & 3,317 \\
Iraq & 3,292 & 3,264 & 3,257 \\
Sudan & 2,744 & 3,002 & 3,104 \\
Iran & 5,204 & 4,055 & 3,068 \\
Other & 32,720 & 35,388 & 40,163 \\
\hline Total & $\mathbf{9 1 , 1 4 9}$ & $\mathbf{1 3 0 , 2 7 7}$ & $\mathbf{1 3 3 , 8 6 0}$ \\
\hline
\end{tabular}

Data in Table 1 above includes all Public Universities and Private HEIs in Peninsular Malaysia only. Previous studies have investigated the challenges faced by international students in their adjustments to host countries. Pandian (2008) revealed that the main challenges encountered by Middle Eastern students were that they possessed the desire to have an improved quality and greater contact with local students, establish stronger bonds of friendships with their local friends and sought greater exposure in terms of the various kinds of social support networks (www.usm.web.my, 2008). The research also found that discrimination, prejudice, tolerance and stereotyping did happen, but these encounters were infrequent and not rampant.

\section{Integrated Threat Theory (ITT)}

According to Hogg (2013) Inter-group relations refers to the way in which people who belong to social groups or categories perceive, think about, feel about, and act towards and interact with people in other groups (https://psycnet.apa.org, 2013). Integrated Threat Theory suggests that an intergroup threat is experienced when members of one group perceive that another group is in a position to cause them harm (Stephan, 2000). The Integrated Thread Theory has examined these four threats which are realistic threats, symbolic threats, intergroup anxiety and negative stereotyping (Stephan, 2002)

Realistic threats are threats to the welfare of the in-group. According to an article from (www. digitalcommons.kennesaw.edu) it includes in-group's political or economic power, or physical well-being. Symbolic threats are threats to the in-group's value system, belief system or worldview (https://oscarybarra.psych.lsa.umich.edu, 2016). While negative stereotypes arise from negative stereotypes the in-group has about the out-group; and intergroup anxiety refers to anxiety the in-group experiences in the process of interaction with members of the out-group, especially when both groups have had a history of antagonism (Croucher, 2017). ITT is used as the framework for this current theory to understand how and why international students react to stereotyping based on the four (4) components of the ITT presented in the figure below. 


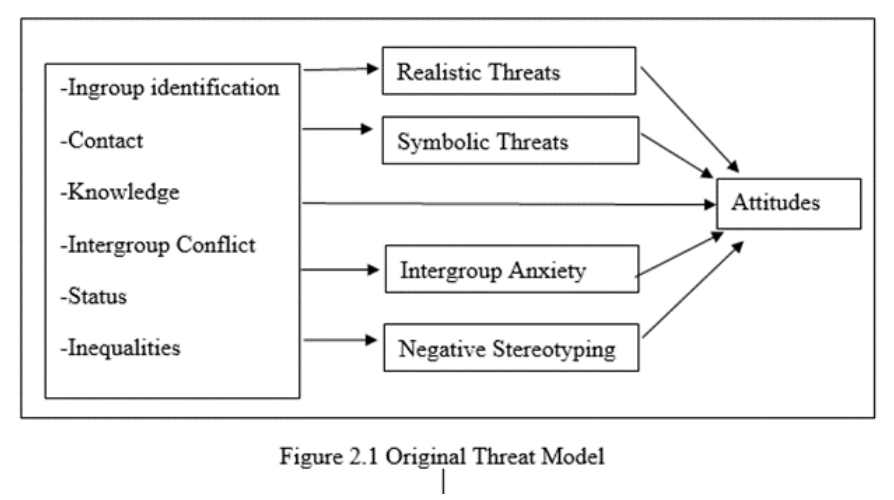

According to Integrated Threat Theory, the four components named realistic threats, symbolic threat, intergroup anxiety and negative stereotyping will cause danger to the in-group. A study conducted by Fritz (2008) examined the cultural adjustment process required of students who were studying abroad. This study examined the acculturation process of students living abroad and the effects of learning a new language, being separated from family and friends, and managing financial problems. The researchers looked at how Integrated Threat Theory addresses the issue of intergroup anxiety, where a student living abroad may experience feelings of being part of the "out" group. Based on the study's findings, the researchers were able to recommend specific program that would help foreign students adjust better to a new culture (www.wikispace.psu.edu, 2017). More importantly, the study found that cultural sensitivity is the most important part of a successful program. A program designed to help Europeans adjust to studying in the U.S. would not be as helpful for a program designed for Asian students for example. Therefore, instead of grouping all foreign students together in a program to help them adjust, programs should be designed for specific cultural groups to help them adjust to their new environment (cited in Tinsley, 2017).

This study analyzes the attitudes of the respondents and possible causes of their behaviors based on the four components of Integrated Threat Theory, namely Realistic Threats, Symbolic Threats, Intergroup Anxiety and Negative Stereotyping. The reasons behind their perceptions are also investigated to relate them with their past experiences that might be related to the six elements mentioned in the theory.

\section{E. Stereotyping among Students in Education Institutions}

According to (Shirase, 2017), stereotype in education institution will lead to academic stress, satisfaction and commitment, self-efficacy and an individual's mental state. Stereotype affected students' identity development and their academic success. A study by Okagaki (2009) examined American Indian and European American students, hypothesized that one of the ways to counter negative stereotypes by students who experienced discrimination is through education. Negative stereotype will not only affect performance (Beilock, Rydell \& McConell, 2007) but also student's attitude and mindset (Rydell et al.). Other than that, continuous negative stereotype will develop socialpsychological anxiety among students and it will lead to the decreasing of academic performance. Students' anxiety on learning and study strategies will also be affected by their attitudes, motivations and beliefs (Yeboah and Smith, 2016). A research conducted in Higher Education and Student Affairs Graduate Preparation Programs by Harris \& Patton in 2018 found that racial stereotypes occurred at the intersections of students' multiple identities and that negative stereotype will reduce students' self-esteem and increase their academic threats.

\section{Methodology}

The study focused on stereotyping experience faced by international students. Qualitative research design seemed to be the most suitable design to meet the purpose of this investigation. A case study is used to pursue in-depth information around the topic. Five international postgraduate students were chosen to participate in semi-structured interviews. Semi-structured interview is selected because it best served to answer the main questions and purpose of the study. The study was conducted at the International Islamic University Malaysia (IIUM), Gombak, Kuala Lumpur, Malaysia. The participants of the study comprised of postgraduate students from different faculties, such as Education, Engineering, Human Science, and ICT. A purposive sampling procedure was used for selecting the participants. Purposive sampling is categorized as a non-probability sample where the respondents were selected based on the specific characteristics of a population and the study objectives. This technique was employed to ensure a fairly equal representation of the variables for the study (https://courses.lumenlearning.com, 2018). The researchers selected the sample based on age, which was between 25 to 40 years old, different genders, different nationalities and most importantly existing postgraduate students. The interview questions were piloted to ensure they were sound and served the actual purpose of the study. Certain terms and arrangements, questions leading to the same answers had been modified. Piloting is important since it can help identify if there are flaws, or limitations within the interview design that 
allow necessary modifications to the major study (Kvale, 2007). The interview questions (see Appendix A) were aimed at eliciting relevant information concerning stereotype and experiences faced by the respondents. The interview questions were divided into three sections: A, B, C.

i. Section A - Demographic information of the respondents.

ii. Section B - Focused on the elements and tendencies of stereotypes.

iii. Section C - Questions regarding the problem/challenges, and ways of overcoming those challenges by the respondents.

The interview session was recorded, transcribed, coded and rearranged in order to gather mutual information in the same category. To establish credibility, the researchers used the member-checking technique to establish agreement on the data gathered. Researchers use this technique in their qualitative research to establish credibility. With this technique, the data, interpretations and conclusions are shared with the respondents in which it allows the respondents to clarify what their intentions were, correct errors, and provide additional information if necessary (Kabir, 2016). During the interviews, the researchers remained neutral in every possible way to avoid being biased towards the topic discussed. The degree of neutrality in this research should be observed to produce valid findings. The researchers also probed moderately while conducting the interviews. This is to maintain objectivity of respondent's responses without getting distracted by researcher's potential bias to fit the narrative. The summary of the respondents' details is listed in Table 2 below.

TABLE 2

BIOGRAPHY OF RESPONDENTS

\begin{tabular}{|c|c|c|c|c|c|}
\hline Respondent & Nationality & Age & Gender & Course & $\begin{array}{l}\text { First } \\
\text { Language }\end{array}$ \\
\hline $\mathbf{A}$ & Somalian & 33 & Female & $\begin{array}{l}\text { Master of Human } \\
\text { Science }\end{array}$ & $\begin{array}{l}\text { Somali and } \\
\text { Arabic }\end{array}$ \\
\hline B & Syrian & 25 & Male & $\begin{array}{l}\text { Master } \\
\text { Education }\end{array}$ & Arabic \\
\hline $\mathbf{C}$ & Pakistani & 26 & Male & $\begin{array}{l}\text { Master } \\
\text { Engineering }\end{array}$ & Urdu \\
\hline D & Sudanese & 36 & Female & $\begin{array}{l}\mathrm{PhD} \text { in } \\
\mathrm{ICT}\end{array}$ & Arabic \\
\hline $\mathbf{E}$ & Thailand & 25 & Female & $\begin{array}{l}\text { Master } \\
\text { Education }\end{array}$ & Thai \\
\hline
\end{tabular}

\section{ANALYSIS, FINDINGS AND DiSCUSSION}

Through rigorous coding and analyses, several themes were derived. The arguments are discussed in light of the framework used, respondents' experiences and extracts from the interviews and also support from the literature discussed at the outset.

\section{A. Positive Stereotype towards Other Races}

All respondents in this study agreed that Malaysia promotes a peaceful culture albeit her multicultural nature. Indeed, Malaysia is a melting pot of diverse cultures. Although both positive and negative stereotypes required people to generalize a group of people, but positive stereotype does not lead or rooted to prejudice due to the positive expression used and it indicate a positive view of a social identity.

A research done by Czopp and his colleagues in 2015 found that positive stereotype can have some positive effects such as helping to boost group's self- esteem and keep them to maintain their favorable impression of others. However, when it comes to interpersonal and group interaction, the effects are predominantly negative (cited in Marco, 2019). The target group of positive stereotypes might feel depersonalized since they need to behave according to a certain expectation. They experienced more anger, annoyance and deal with negative emotions when being associated with certain stigma, even though it is a positive stereotype (Miller, Smith, \& Mackie, 2006).

One of the respondents kept on praising locals throughout the interview by saying all Malays are polite, good in completing their tasks and always respect others.

Respondent B:

"Yes! I adore Malay people.... Actually, it’s like, you know, Malay are all cute and polite...” (B:486)

Respondent C:

"They are very friendly. I also found that Malaysian are very helpful. My supervisor is a Malaysian. He's very friendly and very good. As I heard he is good with other students, he is also good towards me. My lab assistant is a Malaysian sister and she gave me full access as she did to the locals. No problem." - (C:574)

Many researches had different take on Malay culture and politeness strategies. According to Tham (1990), "language is not merely communicative but cognitive as well. Language plays the surrogate for culture, maintaining and reinforcing cognitive patterns and preferences" (Tham 1990, p. 24). Malay and politeness, or to be exact the value of "kesantunan" (virtue) has been embedded in the culture since the dawn of history. It is suggested that the value of the 
Malay culture will affect the way they look at the world around them, thus this orientation is reflected in their politeness strategies.

A research done by Munir, Razif and Sarjit (2010) on politeness of Malaysian undergraduate in a local university found that more than half of the samples ranked politeness as very important. The majority of the respondents claimed that they were always polite when communicating with their dean, lecturers, office clerks and strangers. However, it is interesting to note that they also agreed that there was no need to be polite when communicating among friends (http://eprints.usm.my, 2010)

\section{B. Negative Stereotype towards Other Races}

Two respondents did have negative stereotype towards other races. However, it is notable that those stereotypes they held towards other races did not affect their own academic performances. One of the respondents even admitted that he was swayed by a negative stereotype towards his own race, which is Arab. On the other hand, respondent A, did mention that the negative stereotype that she had towards African mostly were influenced by media and she never experienced any problem with African so far. She even established contact with them.

Respondent A:

"Okay I don't know about other races, but I think African... We have this idea that African are all criminals, they are bad people, we have to avoid them, we are scared of them. - (A:86)

“I don't know, but my friend showed me an article from a Malaysian's newspaper talking about African. I don't remember exactly but it was something really... really bad. It was all the stereotypes written about the typical African with criminal, bad people. We were shock." - (A:98)

She even added that her friend, who is an African used to be harassed verbally when she was walking around KLCC.

"A friend of mine told me she was walking around the KLCC and some locals shouted, "go back to your country!" so I think that's absurd." - (A:62)

Stereotyping towards African or black people is not a new issue. Many research reports stated that racial stereotype towards African students at Higher Education Institutions was still high. Chavous et. el (2003) investigated the relationships among stereotype, expectations, gender, and academic self-concept and performance of African American students and found negative stereotype affected students' academic outcomes. The same result was found in a research conducted by Nicole (2013) entitled "Our biggest challenge is stereotypes: Understanding Stereotype Threat and the Academic Experiences of African American Undergraduates." This research also revealed that stereotype threat acted as the biggest barriers to their academic success.

While respondent A was only focusing on stereotype towards African, respondent B mentioned about his perception towards Bangladeshis based on his personal experience.

Respondent B:

“...but people from Bangladesh are harsh. They don't have that kind of courtesy. Maybe its normal, their culture but they are very harsh. The way they speak, the way they shake their hands, every time I faced people from Bangladesh, I have problem. The first thing first, they are harsh." - (B:373)

One of the many stereotypes associated with Bangladeshis is gender stereotype where women are being put in lessprestigious rank compared to men. A study carried out by M. Niaz Asadullah, Kazi Md Mukitul Islam \& Zaki Wahhaj (2018) on gender stereotype, mentioned:

We examined recent editions of grade 9 English language textbooks. Our analysis confirms a pro-male bias in textbooks. The overall proportion of female to male characters was balanced in Malaysia and Indonesia (44\%) but not in Pakistan (24\%) or Bangladesh (37\%). (https://journals.plos.org, 2018)

It is possible for others who are not familiar to Bangladeshis communication style to perceive it as hasty because of the content of their speech. Other than that, in terms of greeting, men may shake hands if they are of equal status. This handshake tends to be held quite softly and respect is expressed after a handshake by placing one's right hand over one's heart (https://culturalatlas.sbs.com.au, 2016). This clarification of Bangladeshi culture contradicts with the experience faced by the respondent reported in this study.

Considering as part of the society, individual typically would not condemn their culture and people excessively. However, respondent B admitted that even though he is an Arab, he confessed that he hated Arabs' behavior. He specified a few negative characteristics that bothered him as a citizen of his country.

Respondent B:

"Even though I'm Arab, I hate Arab people...I will avoid Arab people and go to Malay." - (B:407)

He added, "Most of the time they are furious, blood boiling [angry], love to fight. Rarely you can find them gentle, they cannot adapt to other cultures, so they misbehave towards others. For me as an Arab, I criticize these people. A lot of people are stubborn, actually. They can't change their behavior." - (B:83)

Research entitled "Arab Postgraduate Students in Malaysia: Identifying and Overcoming the Cultural and Language Barriers" by Al-Zubaidi in 2010 stated that the numbers of Middle Eastern students who migrated to Malaysia to further their studies have increased since the event of 9/11 in 2011. They need to be given the opportunity to understand others' culture, enhance their language skill, adapt with new academic system and possess a contextual awareness of a new community. Thus, due to this significant escalation of numbers, there is a possibility that these Arab students' behavior became more apparent as compared to other nationalities especially when they started to misbehave. 
Based on the Integrated Threat Theory, negative stereotyping happened because of intergroup conflicts. The differences of backgrounds and the feeling of being superior to the others contributed to even more strife within the community. Respondent B perceived the other Middle Easterners as 'stubborn', which might be different from the way he behaves.

\section{Cultural Identity as the Main Reason for Friendship Building}

Three respondents shared their common experiences, where their friendships in IIUM mostly started between people from the same nationality.

Respondent A:

"First... when I came here, I only make friends with my country mates and then later on with international students." (A:07).

Respondent B:

"I make friends with Arab at the first place, but as the time passed by, I became more comfortable to be with Malays." - (B:474)

Respondent C:

"When I first came here, all my Pakistani friends helped me a lot. So, in[during the] initial day, all my Pakistani friends were here and because of the Pakistani society, they recognized me and I got them here and they helped me a lot." - (C:513)

Peer relationship and intimate friendships between Arab mentioned that more communal societies social relationships are important but intimate and exclusive dyadic friendship among peers may be lower. A research entitled "Cultural Identity and the Challenges International Students Encounter" by Zeynab Jibreel (2015) found that international students who were living in United States struggled in the process of adapting to new culture, acquiring new language and understanding a different culture and they face countless difficulties. Thus, international students would be more than grateful if they managed to find someone who shared the same social and cultural identity as them. It is also worth noting from the same research, students started to experience cultural and identity transformation after spending sometime in the host country. International students must adjust to losing their identities (Tseng and Newton, 2002) and to learn a foreign language (Sherry, Thomas, \& Chui, 2010).

It could be said that when international students first came to study abroad, they would be more comfortable to establish contacts only among students from the same nationality but as they are exposed to the other culture and started to mingle around, they tend to be open-minded and eventually build friendship with students from different countries, including locals.

\section{Friendship between International and Local Students}

Throughout the interview, all respondents shared a lot of experiences with their Malay friends. Based on their stories, it could be deduced that international students built positive friendships with locals, and the respondents even have had interpersonal relationships with the Malays. Interpersonal relationship in this context refers to a strong and close bonding of friendship. However, one the respondents did mention about loneliness.

Respondent A:

"Most of international students in that course they feel lonely. Because locals they like you know, go with each other, they don't mix with the international." - (A:79)

This statement is supported by a few researches in that they mentioned that one of the challenges international students need to face is isolation. In many aspects, international students will experience isolation and loneliness when they are studying abroad. Research conducted by Russel et. al (2010) found that over $41 \%$ of international students experienced substantial levels of stress among 900 international students in Australia.

Respondent A also added that she is considered lucky to be part of the communication faculty students. While most of her international friends moaned about the feeling of loneliness due to lack of friends or companies, she had to deal with the same problem. She even expressed her preference in completing assignments with locals instead of international students because according to her, locals are more organized and punctual.

Respondent A:

"People in communication, I think they are more outgoing and more accepting towards different ideas and cultures. It was easier to mix with locals in Faculty of Human Science.”- (A:108).

"I think I like doing assignment with them because they are very organized, yeah, and I can learn a lot of things by doing assignment with local students. They are very organized even in their writing. Yes, very organize.” - (A:154)

Respondent C:

"Locals help me when I have extra courses when I was in my undergraduate level because I switched from mechatronics to automotive, so one course is very difficult so local helped me." - (C: 605)

The same idea was expressed by the second respondent where he stated he would rank Malay as his utmost preference in terms of completing his assignment.

Respondent B:

"Next time I promise myself I only want to choose Malay mates in my group." - (B:462) 
This finding contradicts with the research conducted by Mehar Singh (2012) where he examined 63 undergraduate international students from USM and it revealed that international students often have more friends from their home countries and other countries and not the host country. The findings also showed that aspects of interaction and socialization between international and local students are low. Similar result was also found in a research conducted by Eves (2005) where the findings stated that international students spent significantly less time interacting with local students and local students spent more time interacting with their in-group (local students) than with their out-group (international students).

Two respondents built a strong relationship with Malays even outside of their classroom. One respondent shared her experience living with a local for three weeks because of their project and she was also invited to the Malay wedding ceremony. The respondents were also invited to their friends' house during Hari Raya festival.

Respondent A:

"She even invited me during Eid, even when I was about to go back, she cooked something for me. Like that. She is so so nice! Amazing!" - (A:188)

Respondent B:

"Yes, I was invited and insyaAllah in future I want to invite him to Syria. I want to take him to the beach and Aleppo city. Mutual friendship. I feel very humble to be invited." - (B:505)

Respondent D:

"When I first came here, I decided not to be together with people from my country. I want to be with Malaysian. As you know, I want to make more friends and learn Malay language." - (D:196)

In sum, it can be said that international students will take time to 'warm-up' toward the local students. However, once that are acquainted and connected, they will never forget those experiences.

\section{CONCLUSION}

Based on the data obtained, two out of five international postgraduate students experienced stereotyping. International students have their own stereotype towards other races too, including Malays, be it positive or negative stereotypes. However, the most notable stereotype examined is negative stereotype towards African students where this group of people are usually associated with crime, unethical behavior and bad attitudes. Some international students even admitted that negative stereotypes were given to their own race, such as Arabs being hot-tempered people and good fighter are true. To answer the question regarding international students' experience towards stereotype, this study revealed that they do experience stereotype and it affected their decisions making and emotional wellbeing.

It is suggested that future researchers to replicate similar research in various universities in Malaysia especially in remote areas. In-depth investigations of intercultural area such as biasness, stereotyping, discrimination, prejudice are greatly needed currently especially long-term effects of these problems towards international students. It is also suggested to adapt this study to a larger group of respondents to examine its reliability and validity. A careful exploration of stereotype in these areas may provide more insights into how the intercultural and cross-cultural play a vital role in higher education.

\section{ACKNOWLEDGMENTS}

The authors wish to thank Research Management Centre (RMC) IIUM for awarding the RIGS Grant (RIGS16-3720536).

\section{REFERENCES}

[1] Bartlett, K. (2002). National report on international students in Canada 2000/2001. Ottawa: The Canadian Bureau for International Education.

[2] Beilock SL, Rydell RJ, McConnell AR. (2007). Stereotype threat and working memory: Mechanisms, alleviation, and spillover. Journal of Experimental Psychology: General; 136:256-276.

[3] Bhugra D, Becker M. (2005). Migration, cultural bereavement and cultural identity, World Psychiatry. 2005 Feb; 4(1): $18-24$.

[4] Chavous, T., Bernat, D., Schmeelke-Cone, K., Caldwell, C., Kohn-Wood,L. \& Zimmerman, M. (2003). Racial Identity and Academic Attainment among African-American Adolescents. Child Development, 74: 1076-1091.

[5] Chen, G. a. (1998). Foundations of Intercultural Communication. USA: Allyn \& Bacon.

[6] Chen,G.M. \& Starotsa,W.J. (1998). Foundations of Intercultural Communication. Howard University, Pearson.

[7] Croucher, S. M. (2016). Further development of integrated threat theory and intergroup contact: A reply to Aberson (2015). Communication Monographs, 83, 269-275.

[8] Czopp, A.M., Kay, A.L. \& Cheryan,S. (2015). Positive Stereotypes are Pervasive and Powerful. Perspective on Psychological Sciences, 10(4): 451-463.

[9] Dodd, C. (1991). Dynamics of intercultural communication. USA: Brown Publishers.

[10] Fritz, M. C. (2008). Stressors, anxiety, acculturation and adjustment among International and North American students. Journal of Intercultural Relations, 32 (3): 244-259.

[11] Galloway, F. J. (2005). The Adjustment Problems Faced by International Students in the United States: A Comparison of International Students and Administrative Perceptions at Two Private, Religiously Affiliated Universities. 175-187

[12] Goldstein, E. B. (2011). Cognitive Psychology (3rd Edition). California: Wadsworth Cengage Learning. 
[13] Gudykunst, W. a. (1984). Communication with Strangers: An Approach to Intercultural Communication. New York: Random House.

[14] Harris, J. \& Patton, L. D. (2018). Un/Doing Intersectionality through Higher Education Research. The Journal of Higher Education 90 (3):347-372

[15] Hsiao-ping Wu, Esther Garza, Norma Guzman, "International Student's Challenge and Adjustment to College", Education Research International, vol. 2015, Article ID 202753, 9 pages, 2015. https://doi.org/10.1155/2015/202753.

[16] https://courses.lumenlearning.com (2018).

[17] https://culturalatlas.sbs.com.au (2016).

[18] https://www.moe.gov.my.

[19] Hogg, M. A. (2013). Intergroup relations. In J. DeLamater \& A. Ward (Eds.), Handbooks of sociology and social research. Handbook of social psychology (p. 533-561). Springer Science + Business Media. https://doi.org/10.1007/978-94-007-67720_18

[20] Idrus, F. (2021). Exploring Cultural Intelligence Skills among International Postgraduate Students at a Higher Education Institution. International Journal of Higher Education, 10(4):220-234

[21] Islam KMM, Asadullah MN. (2018). Gender stereotypes and education: A comparative content analysis of Malaysian, Indonesian, Pakistani and Bangladeshi school textbooks. PLoS ONE $13(1)$ : $\mathrm{e} 0190807$. https://doi.org/10.1371/journal.pone.0190807FNisa.

[22] Harris, J.C., \& Linder, C. (2018). The Racialized Experiences of Students of Color in Higher Education and Student Affairs Graduate Preparation Programs. Journal of College Student Development 59(2), 141-158. doi:10.1353/csd.2018.0014.

[23] Jibreel, Zeynab. (2015). "Cultural Identity and the Challenges International Students Encounter". Culminating Projects in English. 23. https://repository.stcloudstate.edu/engl_etds/23. (Accessed 20/1/21).

[24] Naji Abi-Hashem. (2013). Intracultural Communication. www.onlinelibrary.wiley.com

[25] Natalia, K. (2011). Intercultural Communication in an Educational Context: A model for practitioners addressing negative relationships between teachers and Roma families http://docplayer.hu/16971189-Intercultural-communication-in-aneducational-context-a-model-for-practitioners-addressing-negative-relationships-between-teachers-and-roma-families.html.

[26] Kvale,S. (2007). Doing Interview. London: Sage Publication.

[27] Kabir, S.M.S. (2016). Basic Guidelines for Research: An Introductory Approach for All Disciplines (pp.201-275).

[28] Lincoln, Y. S. (2000). Paradigmatic controversies, contradictions, and emerging confluences. London: Sage Publisher.

[29] M. Niaz Asadullah, Kazi Md Mukitul Islam \& Zaki Wahhaj. (2018). Gender Bias in Bangladeshi School Textbooks: Not Just a Matter of Politics or Growing Influence of Islamists, The Review of Faith \& International Affairs, 16:2, 84-89, DOI: $10.1080 / 15570274.2018 .1469821$.

[30] Marco N. (2019). The Effects of Interpersonal Communication in an Organization.

[31] Millican, J., \& Bourner, T. (Eds.) (2011). Student-community engagement and the changing role and context of higher education. Education + Training, 53(2), 89-99. https://doi.org/10.1108/00400911111115645.

[32] Mark Sherry, P. T. (2010). International Students: a Vulnerable Student Population. Higher Education 60(1):33-46.

[33] McLeod, S. (2008). Prejudice and discrimination. Simply Psychology. https://www.simplypsychology.org/prejudice.html.

[34] McNamara, C. (1999). General Guidelines for Conducting Interviews, Authenticity Consulting, LLC,. Retrieved from: http://www.managementhelp.org/evaluatn/ intrview.htm. (Accessed 2/2/21).

[35] Miller, D. A., Smith, E. R., \& Mackie, D. M. (2004). Effects of intergroup contact and political predispositions on prejudice: Role of intergroup emotions. Group Processes \& Intergroup Relations, 7,221-237.

[36] Garcia, A., Miller, D.A., Smith, E. R., \& Mackie, D. (2006). Thanks for the Compliment? Emotional Reactions to Group-Level Versus Individual-Level Compliments and Insults. Available https://www.researchgate.net/publication/48513442_Thanks_for_the_Compliment_Emotional_Reactions_to_GroupLevel_Versus_Individual-Level_Compliments_and_Insults [accessed Jan 13 2021].

[37] Mozena, Lee. (2020). The art of communication is the language of leadership. https://www.zenaconsulting.com/

[38] Manjeet Kaur,M.S, Pandian, A., \& Sarjit Kaur. (2015). International Graduate Students' Experience in Academic Listening Practices in a Malaysian Public University: Challenges and Overcoming Measures. The Asia-Pacific Education Research, 24(1): 91-102

[39] Ministry of Education. (2007). Making a choice about where to study. The experiences of international students in New Zealand: Report on the results of the National Survey, January

[40] Munir Shuib, R. M. (2010). How polite are Malaysian Undergraduates? Asian ESP Journal, 6(1):1-30

[41] Naji Abi-Hashem. (2017). Worldview, The Concept of, Encyclopedia of Psychology and Religion, 10.1007/978-3-642-27771-9, (1-6), (Accessed 10.02.2021)

[42] Naceur, J. (2009). Economic and cultural factors affecting university excellence quality. Assurance in Education, 17(4): 416429.

[43] Okagaki, L., Helling, M.K., \& Bingham, G.E. (2009). American Indian College Students' Ethnic Identity and Beliefs about Education. Journal of College Student Development 50(2), 157-176. doi:10.1353/csd.0.0060. (Accessed 22/2/2021).

[44] Pandian, A. (2008). Multiculturalism In Higher Education: A Case Study Of Middle Eastern Students' Perceptions And Experiences In A Malaysian University. IJAPS, USM.

[45] Rydell, R. J., Rydell, M. T., \& Boucher, K. L. (2010). The effect of negative performance stereotypes on learning. Journal of Personality and Social Psychology, 99(6), 883-896.

[46] Samovar, L. P. (1998). Communication between Cultures. USA: Wadsworth.

[47] Sharabany, R. (2006). Peer relationships and intimate friendships among Arab and Kibbutz children in Israel. New York: Cambridge University

[48] Shirase, L. J. (2017). Stereotype Threat in Higher Education: The Role of Psychological Capital on Student Satisfaction and Commitment. Bear Works Institutional Repository.

[49] Stephan, W. G. (2000). Intergroup anxiety. Journal of Social Issues, 41, 157-175. 
[50] Sumra, K. B. (2011). Study on Adjustment Problems of International Students Studying in Universities of The People's Republic of China: A Comparison of Student and Faculty/Staff Perceptions. International Journal of Education ISSN 19485476, 4(2): 1-20.

[51] Tarry, E. (2011). Is West really best? Social and cultural tensions international students experience having studied at British universities. Journal of Further and Higher Education, 35, 69-87.

[52] Tinsley, A.L. (2017). Intergroup Theories (Integrated Threat, Social Identity, and Social Dominance) https://wikispaces.psu.edu/pages/viewpage.action?pageId=355764849.

[53] Tham,S.C. (1990). Multi-lingualism in Singapore. Two Decades of Development. Census of Population. Monograph 6, Singapore. Department of Statistics. (Accessed 10/2/2021).

[54] Verbik, L. \& Lasanowski, V. (2007). International Student Mobility: Patterns and Trends. http://eprints.usm.my/34574/1/BULLETIN_11_PART_4.pdf. January (Accessed 22/1/2021).

[55] Vogt, W. P. (1997). Tolerance and education: learning to live with diversity and difference. Thousand Oaks: Sage Publications.

[56] W.C. Tseng, F. B. (2002). International students' strategies for well-being. College student journal 36(4):591-597.

[57] Wang, H. L. (2018). Exploring Cross-Cultural Communication Courses in Media Literacy: Case Study of Using the University General Education Program "Citizen Journalism and Actions". International Education Studies 11(10):78-90.

[58] Westwood, M. a. (1990). Academic achievement and social adaptation among international students: A comparison groups study of the peer-pairing program. International Journal of Intercultural Relations 14, 251-263.

[59] Yeboah, A.K.\& Smith, P. (2016). Relationships between minority students online learning experiences and academic performance. Online Learning, 20(4):1-26

[60] Zeeshan, M. (2013). Foreign Students' motivation For Studying in Malaysia. International Journal of Asian Social Science $3(3): 833-846,834$.

[61] Zhang, Shen. (2005). "Stereotype use and rebound following direct instructions and indirect cues: A cross -cultural study". ETD collection for University of Nebraska - Lincoln. AAI3186956.https://digitalcommons.unl.edu/dissertations/AAI3186956. (Accessed 26/01/2021)

[62] Zubaidi, K.O. \& Richards, C.K. (2010). Arab Postgraduate Students in Malaysia: Identifying and Overcoming the Cultural And Language Barriers. Arab World English Journal. 1(1): 107-129.

[63] Zuria Mahmud, S. A. (2010). Challenges for International Students in Malaysia: Culture, Climate and Care. Procedia Social and Behavioral Sciences 7(C) 289-293.

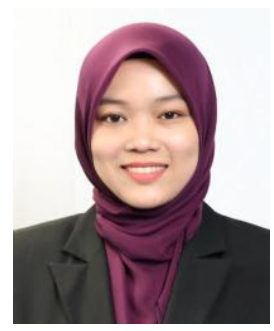

Aini Syahira Jamaluddin is a lecturer at AlBukhary International University, Malaysia. Her research interests include Intercultural and Intra-cultural Communication, English Language Teaching, Korean Language Teaching and a few others.

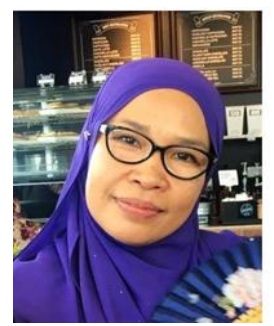

Faizah Idrus (PhD) is an Associate Professor at Kulliyyah (Faculty) of Education, Department of Language and Literacy, International Islamic University Malaysia. Her research interests include but not confined to ELT, Language, Identity and Community, Teacher Education, Cultural Intelligence, Culturally Responsive Teaching (CRT) and a few others. She has written more than 30 articles related to her research. 